AC 2012-5467: A PORTABLE FINITE STATE MACHINE MODULE EXPERIMENT FOR IN-CLASS USE IN A LECTURE-BASED COURSE

Dr. Bonnie Ferri, Georgia Institute of Technology

Bonnie Ferri earned the B.S. in electrical engineering from Notre Dame in 1981, the M.S. in mechanical and aerospace engineering from Princeton University in 1984, and the Ph.D. in electrical engineering from Georgia Tech in 1988. She is currently a professor and Associate Chair of Graduate Affairs in ECE at Georgia Tech.

JillL L. Auerbach, Georgia Institute of Technology 


\title{
A Portable Finite State Machine Module Experiment for In-Class Use in Lecture-Based Course
}

\begin{abstract}
:
This paper presents an experimental module for teaching finite state machine concepts. This module, designed for lecture-based courses, has been used in 11 classes, and assessment has included 471 students. Students design the state machine circuitry as a pre-lab and then build the design on a protoboard in class. The experimental platforms are low weight and powered by 3 AA batteries for portability. The challenge of completing experiments during one 50 minute class session is discussed in this paper. Web support includes an instructional video, a fundamental concepts tutorial, a virtual experiment, on-line quiz questions and assistance for instructors.
\end{abstract}

Keywords: Distributed lab, active learning, finite state machine

\section{Introduction:}

Laboratory experiments are an essential source for instructors who want to include active learning instructional methods in their engineering courses, yet the format is often not well suited to incorporate into lecture-based courses. Lab experiments are generally performed in lab courses in centralized locations. A new extension to the laboratory experience is distributed laboratories, which consist of experiments that can be conducted in a variety of locations such as a standard classroom, common area, or even a dorm room. As such, they can be incorporated into traditional lecture courses or distributed from decentralized locations.

The challenge presented in many engineering programs is how to integrate experimental design into courses that are not coupled with lab components. Since the dissemination of the findings from the groundbreaking study by Hake, engineering departments recognized and implemented a range of innovative pedagogical styles in an effort to advance the value of interactive learning strategies ${ }^{1}$. Hence, the engineering field has experienced a proliferation of "interactive learning" models, many of which report the positive impact on student attitudes and knowledge. Buck and Wage have used an array of what they term "active and cooperative learning (ACL)" methods to enhance courses in signal processing ${ }^{2}$. The model developed by Gleixner and Lackritz included weekly in-class activities for lecture-based introductory Materials Science and Engineering classes ${ }^{3}$. Typically, using a problem-based learning approach means that the entire course is framed around that paradigm, yet data confirming the effectiveness is mixed ${ }^{4}$. For example, a study using problem-based learning in an introduction to electrical engineering course with four topic phases replaced two of the topic lecture-based components with problembased techniques ${ }^{5}$. While there were some promising results, the implementation called for a major course overhaul. The process of incorporating active learning opportunities in lecturebased courses presents challenges for instructors who must often make major course modifications to accommodate these enhancements. 
A primary goal of this research is to develop a model for widespread use of portable laboratories throughout the curriculum as a way of enhancing lecture-based courses. This approach has the potential to have extensive impact on student learning and mitigate the challenges and resistance faced by other engineering education reforms. The limited development required for incorporating hands-on experimental platforms for engineering students to use in the classroom or to take home shows promise towards reaching a realistic modification of lecture-only engineering courses ${ }^{6-11}$.

The Finite State Machine Module described in this paper is one of the modules developed as part of a project funded by the NSF CCLI program to develop labs that can be distributed throughout the curriculum, with emphasis on courses that do not have associated labs. The Teaching Enhancement via Small-Scale Affordable Labs (TESSAL) Center was established to provide cohesive support for the laboratory modules. All of the educational modules in the TESSAL Center share common features:

- Demonstrate fundamental concepts that are often difficult to comprehend in a lecture setting

- Have portable platforms so that they can be performed in class or at home

- Be affordable for mid-sized lecture courses (30-50 students)

- Have web support to promote wide-spread adoption

The TESSAL website ${ }^{12}$, , houses the components of each lab module, which include:

- Experimental platform description

- Tutorial on the fundamental theoretical concepts

- Laboratory instructions for students

- Video or interactive demo to demonstrate operation of the experiment

- Quiz questions that are representative of test questions given in a lecture-based course

- Instructions for instructors to build the platform and to implement the lab

Much of details of the experiment itself were first presented in ${ }^{13}$, but that paper did not present any assessment results. This paper reiterates some of the details of the experiment for completeness sake and presents the assessment methods and results.

\section{Finite State Machine Module}

Digital logic courses incorporate many concepts from binary logic and arithmetic and logic gates through memory units and possibly up through datapaths. One of the difficult transitions for students in the course is the step from combinational logic to sequential circuits since time is now a factor. State machines are difficult for students in that they add a dynamic dimension to the circuit. The output of the circuit depends not only on the inputs, but also on the previous state of the circuit. There are many software simulators of state machines, for example, a MATLAB $^{\odot}$ toolbox $^{14}$ and a Java applet ${ }^{15}$, yet these fall short because students do not have a tangible, hands-on experience that fosters a deeper tie to real life situations nor do they give students experience with a high level system integration activity. The State Machine Module is an interactive approach that provides students with the opportunity to experience firsthand the complex behaviors due to memory in sequential circuits. Moreover, this module reinforces the 
state machine concepts that would be covered in lecture and also provides an in-class problemsolving experience where students design and implement a state machine using simple chips and a protoboard. A standard lecture class period becomes active and dynamic in nature where learning is achieve through inquire and experiential experience.

The associated web site augments the experience by adding multi-media content that parallels the experiment. Since this module is made for use in courses that do not have concurrent labs, it also introduces students to basic physical components.

The general steps of finite state machine design and implementation are listed below. Students are required to perform steps 2)-8) in a classroom setting and step 1) in a prelab. CMOS chips are used for low power, and a battery pack is used for portability.

1) Convert a description of the problem into a state transition diagram

2) Transfer the information from the state transition diagram to a state transition logic table that has inputs consisting of system inputs and current values of the state, $S_{i}$, and outputs consisting of system outputs and next state values, $\mathrm{NS}_{\mathrm{i}}$.

3) Design a combinational circuit to implement the logic in the table.

4) Select the chips to implement the combinational circuit and to implement the memory portion of the state machine, for example, D flip flops can be used to implement registers.

5) Draw a pin diagram to illustrate how to wire the chips together to implement the state machine logic.

6) Insert the chips into a protoboard and wire the ground, high voltage, enables, and clock pins.

7) Complete the circuit by making the connections indicated from Step 5).

8) Test the circuit.

The state machine module consists of a protoboard, a 3-8 decoder, a battery pack (using 3 AA batteries), dip switches, LEDs, D flip flops, and OR gate chips as shown in Figure 1. The experiment requires students to design a state machine from a state transition diagram. This is similar to standard homework and test problems on the subject. However, the module requires that students go one step further and build the circuit in class and test its behavior. They input signals through the dip switches and observe outputs via the LEDs. The experiment is followed by a set of on-line quiz questions that resemble those that might be found on a test in a lecture course on the material.

For the lab experiment, students are required first to build and test the example finite state machine shown in Figure 2. This machine only requires a 2-input OR gate chip, the decoder, and the flip-flop. The pin diagram for the circuit is given to the students and is shown in Figure 3. The students must use the procedure outlined in the sample state machine to design and implement a different machine, such as the one shown in Figure 4. 


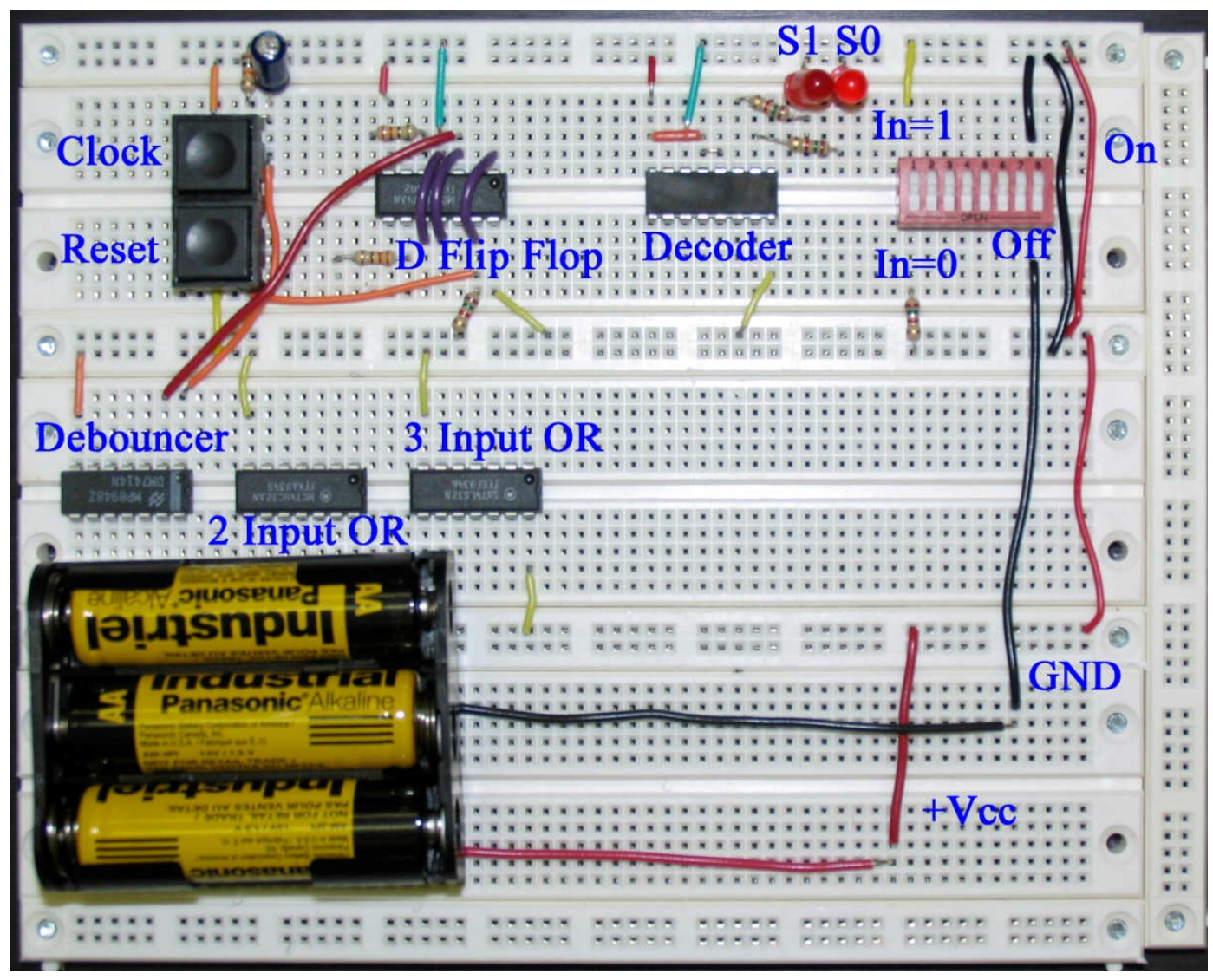

Figure 1: Partially pre-wired protoboard for a state machine implementation. ${ }^{12}$

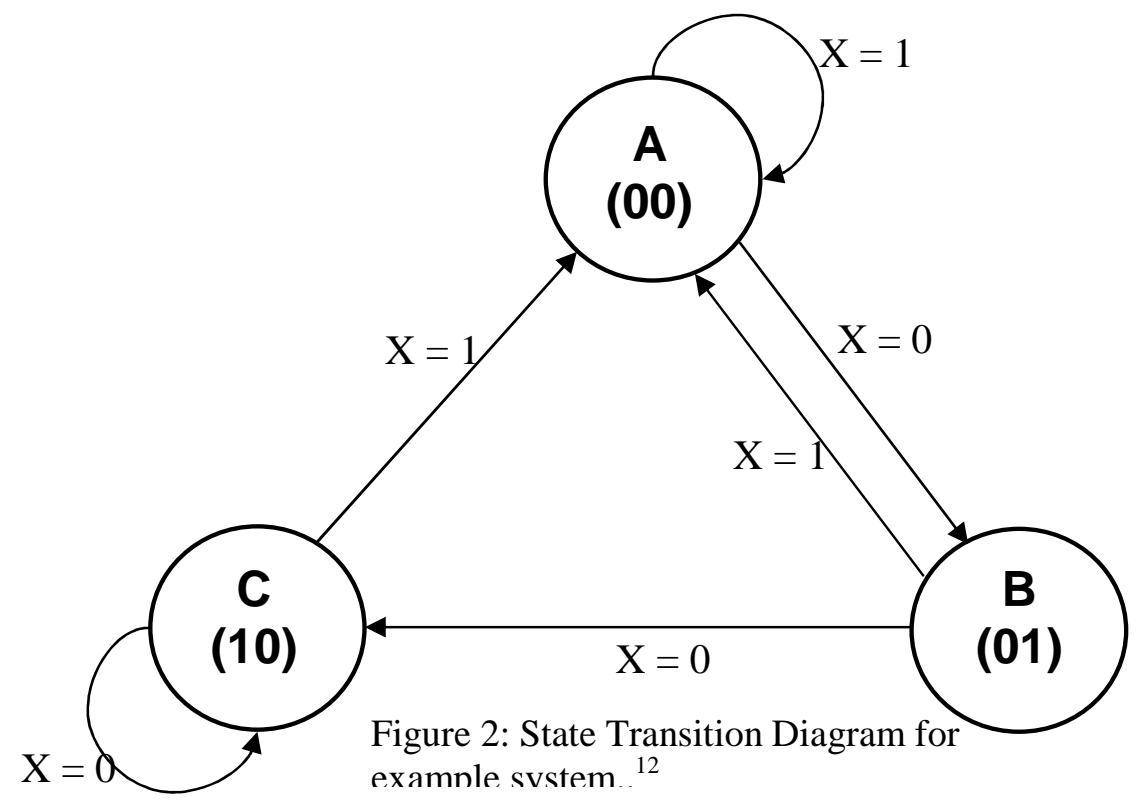




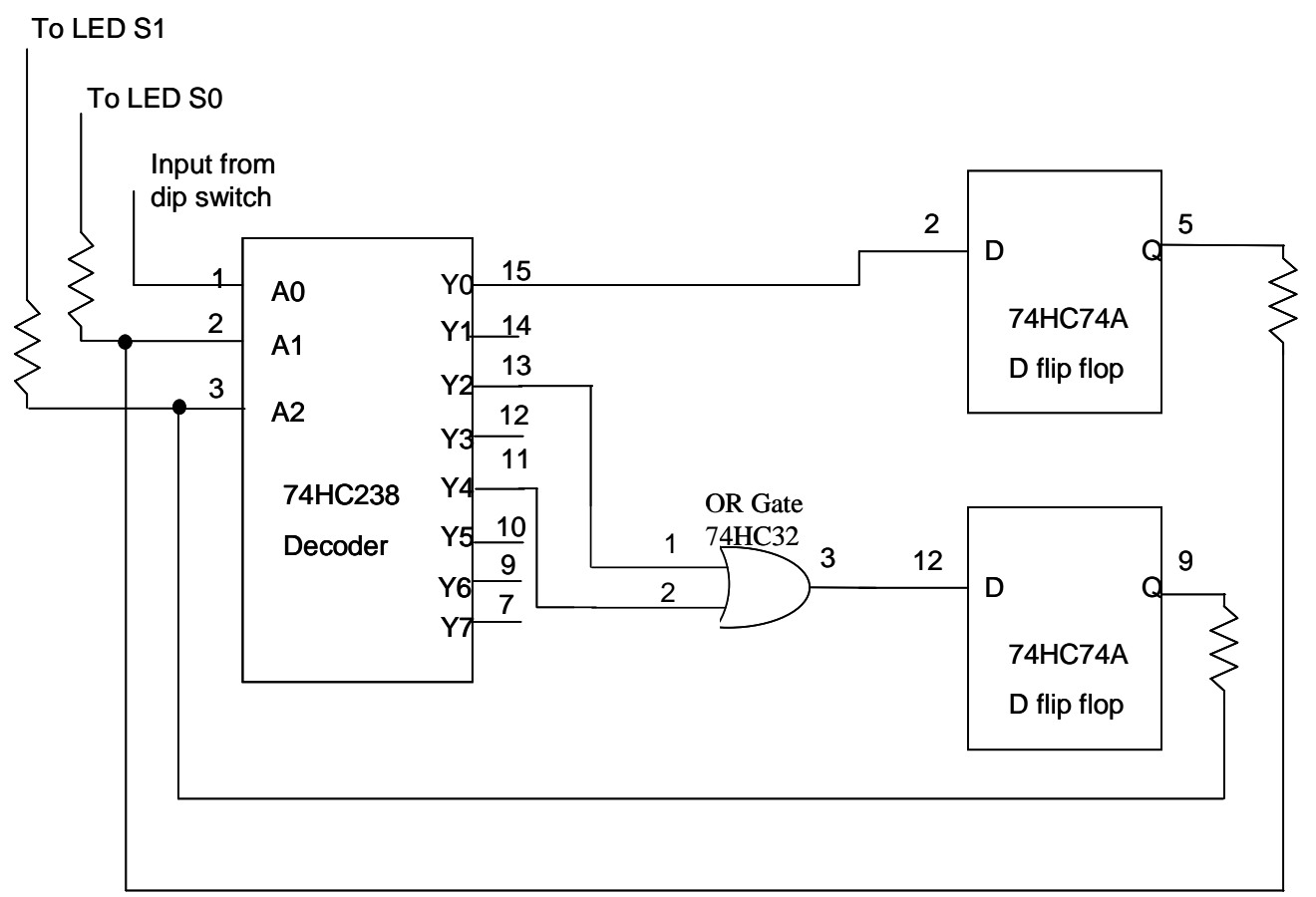

Figure 3: Pin diagram for the example system. ${ }^{12}$

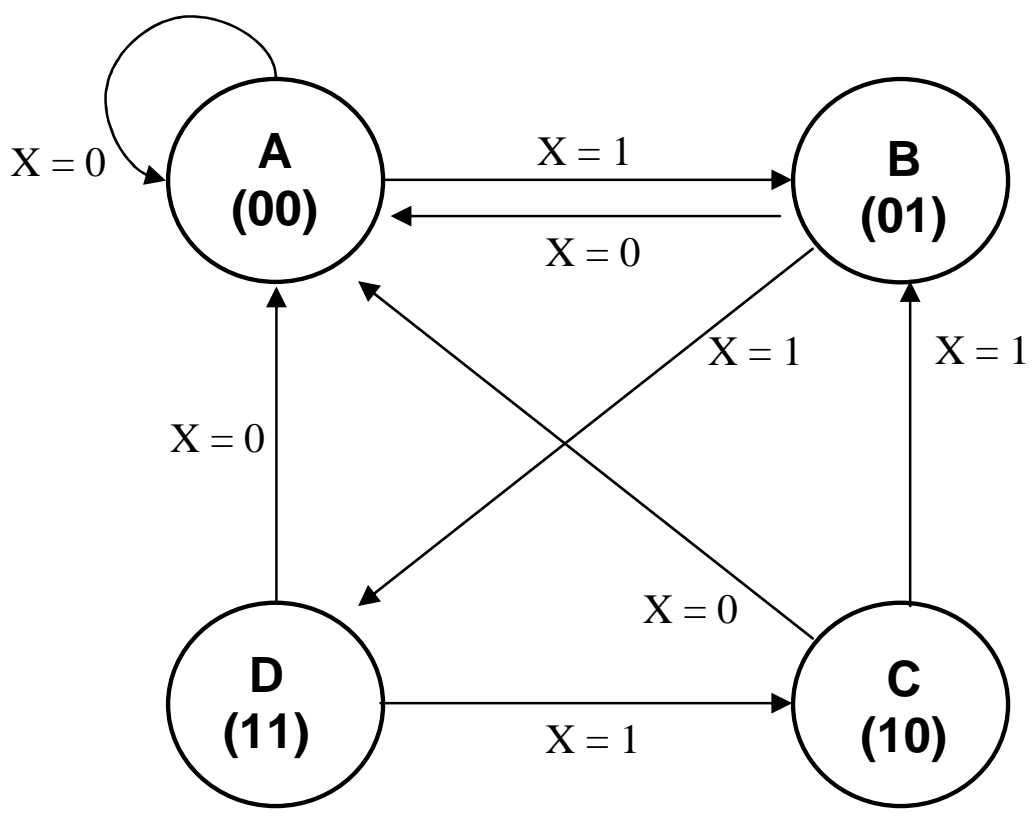

Figure 4: State machine assignment for design and implementation. ${ }^{12}$ 


\section{Supplemental Resources}

The intent of the supplemental resources is both to enhance the learning experience of the students and also to provide a "package" of materials for instructors to use. The "package" creates a more comprehensive unit and gives instructors several sources to use for students to earn points. Thus, in addition to the experimental platform, the components of the Finite State Machine Module include:

Fundamental Concepts tutorial - containing a summary of state transition diagrams and state tables, decoders, registers, and state machine circuit.

Pre-lab and Lab Instructions - the prelab is to be completed prior to class and the remainder of the lab is to be completed in class

Instructional Video - introduction to protoboards and how to wire the example circuit; video is available for viewing online or for downloading to an IPOD.

Virtual Experiment - a Flash demo is available that is built upon the image of the partially wired protoboard shown in Figure 1. Students can use their mouse to complete the wiring for the example state machine. They can then test the circuit's operation by clicking on the input dip switch (to toggle between an input of 0 and 1), and the circuit's clock button. The LEDs "light up" in the image according to the example state machine logic.

Quiz Questions - questions representative of those found in tests on this material modified to be completed in an on-line manner using Flash. A sample quiz question is shown in Figure 5. Note that there are several parts to this problem, and the figure only shows the first part. (Note that this component is formative assessment where students are tested on their understanding with the goal to guide them on points lacking in their understanding.)

Instructor Resources - parts list, schematic of circuit, best practices for implementation, FAQ for common student mistakes. 
A state machine has the following truth table where $\mathrm{A}$ is the input.

a) Draw the state transition diagram.

b) Use a decoder to design the combinational logic.

c) Show the schematic of the entire state machine including the decoder.

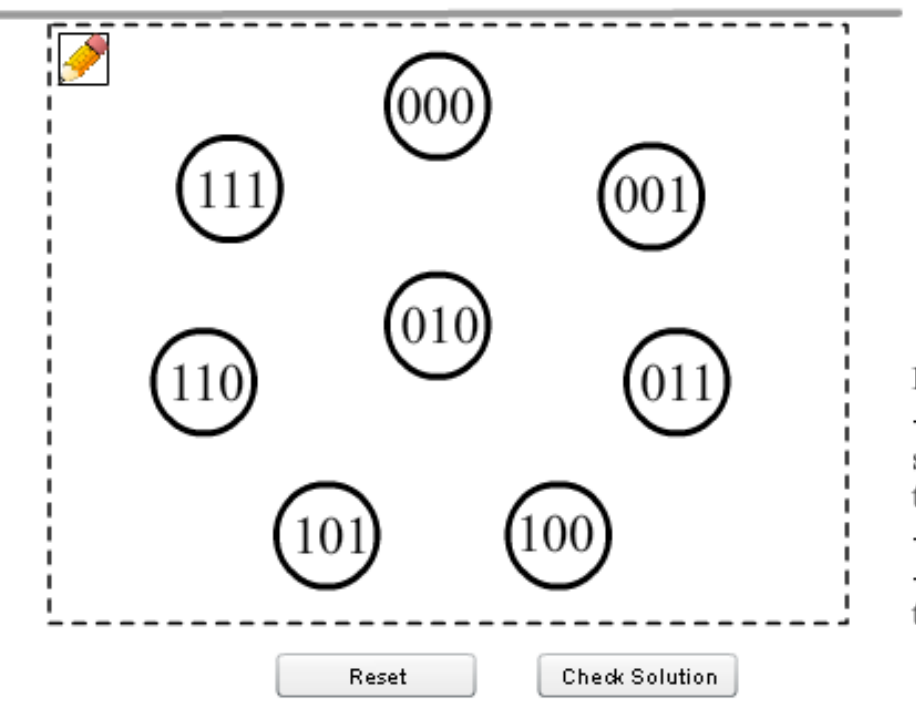

\begin{tabular}{|l|l|l|l|l|l|l|}
\hline A & S2 & S1 & S0 & NS2 & NS1 & NS0 \\
\hline 1 & 0 & 0 & 0 & 0 & 1 & 0 \\
\hline 1 & 0 & 0 & 1 & 1 & 0 & 0 \\
\hline 1 & 0 & 1 & 0 & 0 & 0 & 0 \\
\hline 1 & 0 & 1 & 1 & 1 & 1 & 1 \\
\hline 1 & 1 & 0 & 0 & 1 & 0 & 0 \\
\hline 1 & 1 & 0 & 1 & 1 & 0 & 0 \\
\hline 1 & 1 & 1 & 0 & 0 & 0 & 1 \\
\hline 1 & 1 & 1 & 1 & 0 & 1 & 1 \\
\hline 0 & $X$ & $X$ & $X$ & 0 & 1 & 0 \\
\hline
\end{tabular}

Hint:

- Click pencil to connect states ( by clicking start point, end point and arc control point), then input A value near the line.

- Click Reset to redraw the digram.

- Click the Check Solution button to compare the diagram.

Figure 5: Online quiz question, written in Flash. ${ }^{12}$

The video takes students through the pin diagram shown in Figure 3 and gives them the introductory steps needed to implement the sample state machine on the partially wired protoboard shown in Figure 1. Students may try to wire the circuit prior to class by using the virtual experiment built using Flash.

\section{Implementation}

The State Machine Module is currently used in ECE 2030 Introduction to Computer Engineering courses at Georgia Tech. A major implementation challenge is finishing the experiment in a one-lecture time slot, especially if this is the first time they have been exposed to protoboards. Completing the in-class portion in a 50-minute class period is very difficult, but a 75-minute lecture is long enough to run the experiment for the state machine shown in Figure 4. To accomplish this, students must complete the pre-lab before class where they design the state machine logic and circuit. Students are also asked to view a seven-minute instructional video that gives an introduction to protoboards and to the experimental platform. These platforms are partially built and pre-wired for the students. The platform is given to students in the form shown in Figure 1: the protoboard with the battery pack mounted, chips inserted, dip switches inserted with appropriate pull down resistors, push buttons (for toggle and clear) with antibounce filters. The ground and high voltage are pre-wired as well as the enable, the clock and the reset lines. In this way, the student can see the implementation aspects, such as debouncing, but need concentrate only on the connection of wires that implement the state machine transition logic. 
Students are given the website for the State Machine module and asked to follow these steps:

1. Read the Fundamental Concepts document

2. Download and print the Lab Instructions (includes the prelab)

3. Complete the state machine design in the pre-lab

4. View the video (the description of pin diagrams is useful for completing the pin diagram required in the pre-lab)

5. Practice the wiring procedure on the virtual experiment and test its operation

6. Bring the lab instructions to class and complete the lab in class (wire the example circuit and their designed circuit)

7. Do the online quizzes for the material

At the beginning of class, students are partnered with their neighbor (2-person groups), and each group receives one board and 8-10 extra wires. The introductory video is shown for those who need it. Ideally, all students will view the video in advance of class. They are asked to complete the lab in-class and turn in one lab write-up per group.

Teaching Assistants play a critical role in the smooth implementation of this experiment. They are asked to run through the lab on their own before class and to test the boards. They also bring the boards to class. A ratio of one TA to be available in class per 10 (two-person) teams is recommended. They are asked to circulate around the class during the experiment as students are encouraged to ask questions. (The course instructor can substitute for one TA.) Students must demonstrate their circuits, both the example circuit and their designed circuit, to the TAs. The demonstration consists of running through a set sequence of inputs and recording the resulting outputs. The TAs answers questions and sign off on the demonstrations.

Students begin completing the experiment at the 30 minute mark with the majority finishing around 50-60 minutes. It takes some students the entire class period to finish the experiment. Alternate forms of the state machine are available that are a little simpler and would require less time, hence would be suitable for a 50-minute lecture. The difference is that the machine shown in Figure 4 uses a 3-input OR gate while the example circuit and the alternative machines use only 2-input OR gates. This added complication of the 3-input OR gate is harder for some students than others to comprehend; hence the large variation in completion time.

\section{Assessment and Discussion}

The State Machine Module was developed for courses that cover digital logic, which is taught by several different instructors. Early in the implementation phase, an assessment plan was developed that specified on-going evaluation in ECE 2030 Introduction to Computer Engineering courses during the first three years of implementation. Data has been collected from 11 classes over five semesters during that period. Six of those classes include three control and three experimental sections where each pair is taught by the same instructor. This is a required course for both Computer Engineering and Electrical Engineering majors. The course is also a technical elective for Industrial and Systems Engineering majors, so the makeup of any particular class tends to be a mix of these majors. Within the context of curriculum-wide reform by using portable laboratories throughout the curriculum, the value of the state machine module to 
increase students' understanding of state machine concepts and design, and enhance their interest and enthusiasm in learning the course material is assessed. The assessment of using the module consists of two primary strategies: reviewing test performance on those questions that correspond to the material covered by the experiment and conducting student surveys about their interest and understanding of the material as well as feedback about the experiment itself.

Since finite state machines can be difficult to understand, a survey conducted at the end of each semester asked students to compare their understanding of those concepts to that of other topics in the course. The survey data presented in Table 1 shows that for six classes (three pairs of experimental and control classes and each pair taught by the same instructor), higher percentages of students in each of the control classes report that they did not understand the state machine material as well as other material in the class. While all three pairs demonstrate differences, for the spring 2008 pair, $82.8 \%$ of the students in the control group reported that their understanding of protoboards/breadboard was not as good as other topics in the course compared to $5.7 \%$ in the experimental group.

\begin{tabular}{|l|c|c|}
\hline \multicolumn{3}{|c|}{$\begin{array}{c}\text { Table 1 } \\
\text { Percentage of student reporting that their understanding of } \\
\text { protoboards/breadboard was not as good as other topics in the course }\end{array}$} \\
\hline & Control & Experimental \\
\hline Pair \#1 Spring semester 2008 & $82.8 \%$ & $5.7 \%$ \\
\hline Pair \#2 Fall semester 2008 & $74.3 \%$ & $47.6 \%$ \\
\hline Pair \#3 Fall semester 2009 & $66.7 \%$ & $31.9 \%$ \\
\hline
\end{tabular}

Another interesting point regarding the data in Table 1 is that the same instructor taught the spring and fall 2008 sections, and it was the first semester using the portable laboratory experiment that the highest percentage of students reported the better understanding of the material covered by the lab. One difference among the experimental sections is completion of the pre-lab state machine homework assignments. For the spring 2008 students, only one student did not complete the homework and only one student of 39 reported that there was inadequate inclass preparation for the lab. In fall 2008, 9 students out of 24 did not complete the pre-lab assignment. Not only were students not as conscientious about the pre-lab assignment, but close to half reported that they needed more preparation. Of all 6 sections, this one had the most comments that pertained to the need for more time, better preparation and more instructions.

Surveys were also conducted at the beginning of each semester when students were asked a series of questions about their knowledge and experience in specific topic areas. This was one way to ascertain if the control and experimental student cohorts were similar in their selfperceptions before taking the course. One of the questions asked if students had experience working with protoboards before taking the class. There were only a handful of students who reported any experience, and there is no evidence that the experimental classes had more students with that experience.

Survey data from the other sections of Introduction to Computer Engineering support the need to complete the pre-lab assignments and to manage efficiently the execution of the experiment. In another section with a different instructor who did only the experimental class, 7 of 28 students 
did not do the pre-lab assignment and $40 \%$ of the students reported they did not understand protoboards as well as the other material. In a different section taught by another instructor who reported that the pre-lab video did not work and the instructor did not attend class, $42 \%$ of students did not understand protoboards as well as other material. However, several of the comments stated that students wanted to see more in-class experiments. In analyzing survey data for the 8 sections that had the portable lab component, the data suggest that the classes where the experiment was managed efficiently and students completed the pre-lab homework were more successful in terms of understanding the complex topic and concepts covered by the lab.

One additional noteworthy finding from the survey data is the enthusiasm expressed by students in a section of the course where several supplements to the experiment were available. In this section of Introduction to Computer Engineering, the instructor had not only a pre-lab homework assignment and on-line video-tutorial, but additional on-line supplements. While $30 \%$ of the students reported less understanding of protoboards than other topics, all of the students reported adequate preparation for the laboratory and 8 of 13 comments suggested having more experiments like that one. Since this class had 6 associated supplements, additional analysis will be needed to determine if any supplements are more effective than others in helping students understand protoboards.

Analysis of test performance provides additional insight about the impact of using the experimental platform in class. For one of the control and experimental pairs, students in each class were given state machine quizzes as well as a question on the final exams covering the same concepts. On the state machine quiz, there were basically no differences between the two classes, with mean scores of 30.7 in the experimental class and 29.7 in the control class (out of 40 points.) Performance in each class on the final exam question about state machines yielded similar findings. Looking more closely at test performance addresses a potential complication often cited when using an entire lecture slot for a hands-on experiment that pertains to the material that is not covered in class due to the time used for the experiment. A negative impact on final exam scores in the experimental class is not found. The table below shows performance on the final exam in each course section both with and without the state machine question included in the totals. Scores used to calculate the mean excluding the state machine questions were normalized for ease of comparison.

\begin{tabular}{|l|c|c|}
\hline \multicolumn{3}{|c|}{ Table 2 } \\
$\begin{array}{l}\text { Comparison of Mean Scores on Final Exam in } \\
\text { Control and Experimental Class Sections }\end{array}$ \\
\hline & $\begin{array}{c}\text { Mean Including State } \\
\text { Machine Q. }\end{array}$ & $\begin{array}{c}\text { Mean Excluding } \\
\text { State Machine Q. }\end{array}$ \\
\hline Hands-on Experiment Class Section & $71.6 \%$ & $70.1 \%$ \\
\hline Lecture-only Class Section & $69.8 \%$ & $68.1 \%$ \\
\hline
\end{tabular}

What these findings indicate is that students performed similarly in both class sections and there were no apparent negative consequences to replacing an entire lecture period with a hands-on experiment that provide an active learning experience. Additionally, when the test score data is 
considered along with the survey data from both sections, students from the experimental class report more confidence, enthusiasm and mastery over the state machine material.

Analysis of test performance in another section of the same class (although not part of the quasiexperimental design described above) reveals a somewhat different pattern and may reveal the impact of other factors, or interventions, on test performance. In this section of the course, all supplemental components were fully implemented and students were given adequate notice when all assignments were to be completed. The scatter plot in Figure 6 depicts student performance on the state machine question on the final exam and performance on the remainder test questions. All test questions were designed to be of equal level of difficulty. Based on the distribution, students tended to perform better on the state machine problem compared to the other questions on the test.

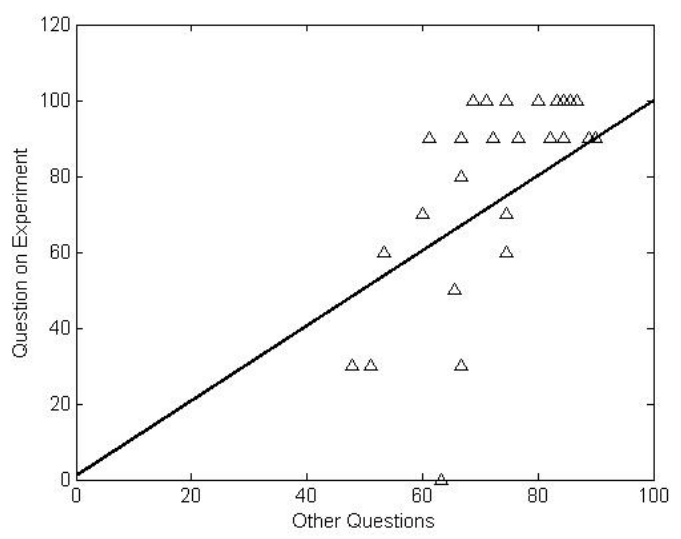

Figure 6: Student Grades on Final Exam and State Machine Question

The survey data from this same class may in part explain the high performance on the state machine question. On the end-of-course survey, students were asked a series of questions about the use of the supplemental materials. For example, $87 \%$ of students reported that they did the pre-lab state machine assignment before the in-class experiment, all but one student viewed the video tutorial before class and $82 \%$ said they read the on-line fundamental concepts tutorial. Moreover, all students responded that there was adequate preparation for the in-class experiment. The comments from this student group were all positive with the only complaints that students need more hands-on assignments.

Moving forward, further analysis of how the supplemental materials are utilized will help us better understand the ability to achieve the widespread integration of portable labs in lecturebased courses.

The feedback from the students and from the faculty using these modules has been so positive that the state machine modules have now become mandatory for the course and have become part of the revised syllabus starting in Fall 2012. While protoboards themselves were only a tool to address the true topic of physical state machines, students did receive a valuable introduction into physical systems. A modification that we have adopted in future offerings of the course has been to allow students to finish the lab in TA office hours if they did not finish the lab during class period. The fastest students start finishing the lab in about 25 minutes and the majority of 
students finish on time, but some students do not finish the lab during the 50 minute class period. The time pressure does intimidate them as does working with a protoboard and real equipment for the first time, so having a safety net of being able to complete the lab later relieves stress during the lecture period. It remains to be seen if the added time adds to understanding of material, retention of knowledge, or comfort level with the equipment.

Acknowledgement: This work was supported by NSF CCLI Project Number 0618645. The authors would like to thank Hongyi Qu for his work in developing the website.

\section{References:}

${ }^{1}$ R.R. Hake, "Interactive-engagement v. Traditional Methods: A Six-thousand-Student Survey of Mechanics Test Data for Introductory Physics Courses," American Journal of Physics vol. 66, pp. 64-74, 1998.

2 John Buck and Kathleen Wage, “Active and Cooperative Learning in Signal Processing Courses,” IEEE Signal Processing Magazine, pp. 76-81, March, 2005.

${ }^{3}$ Stacy Gleixner and Hilary Lackritz, "Use of Collaborative Learning Exercises to Increase Student Motivation and Learning in an Introduction to Materials Engineering Course," ASEE Annual Conference Proceedings, 2004.

${ }^{4}$ Michael Prince, "Does Active Learning Work? A Review of the Literature," Journal of Engineering Education, vol. 93(3), pp. 223-231, 2004.

5 Aman Yadav, Dipendra Subed, Mary Lundeberg and Charles Bunting, "Problem-based Learning: Influence on Students' Learning in an Electrical Engineering Course," vol. 100(2), pp. 253-280, 2011.

${ }^{6}$ R. Dua, J.E. Seiffertt, B. Blaha, K. Gupta, V. Satagopan, J.R. Stanley, D. Beetner, and D.C. Wunsch,, 2005, "Hands-On Projects and Exercised to Strengthen Understanding of Basic Computer Engineering Concepts," Proceedings of the American Society of Engineering Education Annual Conference \& Exposition, Portland.

${ }^{7}$ W. Durfee, P. Li, and D. Waletzko, 2005, “At-Home System and Controls Laboratories,” Proceedings of the American Society of Engineering Education Annual Conference \& Exposition, Portland.

${ }^{8}$ B. Ferri, J. Auerbach, J. Michaels, D. Williams, 2010, "TESSAL: Portable Distributed Laboratories in the ECE Curriculum," 2010 ASEE Annual Conference and Exposition, June, Vancouver.

${ }^{9}$ B. Ferri, S. Ahmed, J. Michaels, E. Dean, C. Garvet, S. Shearman, "Signal Processig Experiments With LEGO MINSTORMS NXT Kit for Use in Signals and Systems Courses," Proceedings of the American Control Conference, St. Louis, pp. 3787-3792.

${ }^{10}$ R.W. Hendricks, K.M. Lai, and J.B. Webb, 2005,"Lab-in-a-Box: Experiments in Electronic Circuits That Support Introductory Courses for Electrical and Computer Engineers," Proceedings of the American Society of Engineering Education Annual Conference \& Exposition, Portland.

${ }^{11}$ D.H. Litwhiler, T.D. Lovell, 2005, “Acoustic Measurements Using Common Computer Accessories: Do Try This at Home," Proceedings of the American Society of Engineering Education Annual Conference \& Exposition, Portland.

12 (TESSAL Website, 2012), “Teaching Enhancement via Small-Scale Affordable Labs Center”, http://www.ece.gatech.edu/research/tessal/index.html accessed 3/1/12 
${ }^{13}$ B. Ferri, J. Auerbach, H. Qu, 2010, "Distributed Laboratories: A Finite State Machine Module," Proceedings of the World Congress In Computer Science, Computer Engineering and Applied Computing, International

Conference: Frontiers in Education Conference on Computer Science and Computer Engineering, July, Las Vegas, NV.

${ }^{14}$ (Mathworks, 2012), "Overview of Mealy and Moore Machines," http://www.mathworks.com/access/helpdesk/help/toolbox/stateflow/ug/bqtktf3-1.html, The Mathworks, accessed $3 / 1 / 12$.

${ }^{15}$ (Java, 2012), "Finite State Machine Simulator," based on an applet by Kyril Faenov http://www.cs.virginia.edu/ akn8c/t/ accessed 3/1/12. 